\title{
THE EFFECTS OF DIELECTRIC VALUES, BREAST AND TUMOR SIZE ON THE DETECTION OF BREAST TUMOR
}

\author{
Nuşin UNCU, Emine AVŞAR AYDIN
}

\begin{abstract}
Although breast cancer is the second main cause of female deaths after lung cancer, early diagnosis plays a crucial role to diminish the death rate. Many techniques have been improved to detect the cancerous cells. At different microwave frequencies, the malignant cells indicate different electrical characteristics as compared to the normal cells. According to these frequencies, the breast tissue is more permeable than other tissues such as the brain and muscle. Due to this property of the breast tissue, microwaves can be used for the detection of breast cancer. In this study, the breast prototype was modelled using the CST STUDIO SUITE electromagnetic simulation software with respect to different breast size, tumor size and dielectric values tested at a range of the $0-3.0 \mathrm{GHz}$ frequency. The objective of this paper is to investigate the effects of each factor and the interactions of factors on detecting cancer cells using the factorial analysis. The results indicate that the factors such as fat and skin permittivity, tumor and breast sizes are more effective in the detection of breast tumor. Although the effect of fibro permittivity is not significant alone, there are considerable interaction effects of a large breast size and small tumor size through low-to-high values of fibro permittivity. Furthermore, the combinations of a breast radius smaller than almost $8.5 \mathrm{~cm}$ with a high level tumor radius and breast radius larger than $8.5 \mathrm{~cm}$ with a low level tumor radius are desirable for lessening the return loss value.
\end{abstract}

Keywords: dielectric properties; factorial design; factor effects; microwave breast cancer detection

\section{INTRODUCTION}

Breast cancer is one of the main reasons of female death worldwide [1-5]. It is a key factor that the tumor be recognized in the early stages for a higher survival rate. In the last decade, the Microwave Imaging System [6-10] has been the focus of many researchers because of some drawbacks of the existing breast cancer detection techniques which are the magnetic resonance imaging (MRI), X-ray mammography, and ultrasound. Among these breast cancer imaging techniques, the MRI cost is very high and it also only has the advantage of screening evaluation before surgical operation. The X-ray mammography has hazardous radiation, false positives and painful breast compression. The microwave-based breast cancer imaging is one of the most promising methods for detecting breast cancer during its early development. This method relies on the differences in the dielectric properties of benign and malignant breast tissues which are skin, fat, fibro glandular, tumor $[1,2]$.

Dielectric properties of a material are obtained by measuring its ability to interact with electromagnetic energy [11]. The electric and magnetic forces generated by electromagnetic (EM) fields can cause changes in the interaction results. In addition to that, these properties tell us a lot about the mechanism of interaction of electromagnetic fields with various biological systems, including biopolymers, membranes and cells.

An EM field primarily acts upon components within the materials in biological tissues. These materials have a net electric charge and/or electric dipole moment. The main source of electric dipole moments in tissues belongs to polar molecules. The other additional sources are protein structures, muscles, fat, etc. Due to the fact that the electrical properties of a tissue are determined by such a wide variety of components, as reflected in different dielectric dispersions, these properties exhibit significant variations.
The thermal phenomena of conduction, convection and radiation play only a secondary role in temperature equilibrium, when an object is exposed to microwaves. The reason for this is that the release of heat is so instantaneous.

In a research study, the data from 15 patients showed that the values of dielectric properties for malignant breast tissues at 1-2 GHz are 3-5 times higher than the normal breast tissues [1]. In another study, 12 measurements indicated that dielectric properties of malignant breast tissues are roundly 10 times greater than the normal breast tissues since malignant tissues have a lot of water and are also more active in relation to the normal tissues.

Malignant tumors have higher relative permittivity and conductivity values than the normal breast tissue. These values can be as high as 10 times for adipose fat, but drop to a contrast of around $10 \%$, mainly in conductivity, for fibro glandular (FG) tissue. This contrast has posed a challenge for the microwave imaging community as FG tissue is where most breast tumors originate [12]. Understanding the mechanisms that result in the high permittivity and hyperconductivity of tumors is therefore a crucial part of breast cancer imaging. There have been many factors with difference in dielectric properties between the normal and malignant tissues.

One of factors is necrosis [13]. It is usually found in malignant breast tissue. Necrosis leads to the breakdown of cell membranes and thus a larger fraction of tissue can carry current at low frequencies, which decreases the capacitance of the tumor.

The second factor is the charging of the cell membrane [13]. In breast carcinoma, fat lobules are replaced with fibroblastic proliferation and epithelial cells are accompanied by a variety of alterations at the transformed cell surface. Cancer cell membranes have a reduced potential and have the ability to absorb positive ions because they have a higher negative surface charge. As a result, the conductivity of the 
malignant tissue is increased because of the displacement and rotations of this mobile charge by the microwave field.

The relaxation times which are a third factor in malignant tissues are larger than those in the normal tissues resulting from the increased motional freedom of water [13]. The last one is sodium concentration and water content [13]. The sodium concentration in cancer cells is higher than that in normal cells. The high sodium concentration alone yields higher permittivity and conductivity values for malignant tissue. This higher sodium concentration also affects the cell membrane potential and causes the malignant tissue to retain more fluid. This retained fluid is in the form of bound water, which has higher permittivity and conductivity values. Malignant tissue therefore has a higher water content ratio than that of normal tissue, which coincides with higher values of permittivity and conductivity than normal breast tissue at the same microwave frequency.

The understanding and development of medical microwave techniques needs knowledge of the microwave dielectric properties of human tissues. There have been many data on the dielectric properties of female human normal/malignant/benign and surrounding breast tissue.

Dielectric properties of breast carcinoma and the surrounding tissues were measured [14]. The experiments were performed at the frequencies from $100 \mathrm{kHz}$ to $100 \mathrm{MHz}$ at $37^{\circ} \mathrm{C}$ using an automatic network analyzer and an end-ofthe-line capacitive sensor. Using a computer program, the cole-cole parameters were found by curve fitting. Tissues were divided into three main categories. These were the central part of the tumor, the tumor surrounding tissue, and the peripheral tissue. Tumor specimens were taken from seven different patients. From each specimen, depending on its size, 2-6 samples in the form of thin disks were excised. The number of samples was 28. The duration of all measurements was $4 \mathrm{~h}$ after the surgery. As seen from Table 1 , measurements showed significant differences in dielectric properties between the samples taken from different locations. Surgical pathology reported the following diagnoses: A-infiltrating ductal carcinoma without metastases, B-infiltrating ductal carcinoma, C-infiltrating ductal carcinoma with focal papillary component, Dinfiltrating carcinoma consistent with lobular carcinoma, Einfiltrating lobular carcinoma, F-infiltrating ductal carcinoma, G-infiltrating lobular carcinoma.

Using a resonant cavity technique, complex permittivity of in vitro diseased and non-diseased human female breast tissues were measured at $3.2 \mathrm{GHz}$ [15]. Both dielectric properties and water contents of these tissues were found. Experimental data were compared with the models predicted from mixture equations.

Hitherto, breast cancer detection studies were carried out using dielectric properties; however the effect of dielectric properties has not been investigated. A 3D-breast was modeled by using the CST STUDIO SUITE electromagnetic simulation software and analyzed by using different dielectric properties and different breast and tumor sizes based on experimental design analyses results in the frequency range from $0 \mathrm{GHz}$ to $3 \mathrm{GHz}$.
Design of Experiment (DOE) techniques have been used extensively in many different scientific fields. These techniques are beneficial for getting accurate statistical inferences for revealing the effects of factors on a process with less experimenting rather than considering all the combinations of factors. One of the DOE technique applications is found in [16] for analytical chemistry. In another study [17], a considerable decrease of patient dissatisfaction was given for the emergency room. [18] applied the factorial design technique to see the effects of prophylactic antiemetic interventions on the risk of postoperative nausea and vomiting of the surgery patients. Another case study on the effect of treatment factors on the quality of life of patients with breast cancer is found in [19]. In this study, $2^{k}$ factorial design is used to reveal the effects of factors and their interactions on the success of detecting breast tumor.

The outline of the paper starts with the introduction section. It is followed by illustrating the factors considered in breast cancer detection and applying simulation and the general factorial design. In the third section, significant effects of factors and their interaction graphs are given. Finally, further suggestions on the improvement of breast cancer detection are explained in the conclusion part.

Table 1 Computer fitted dielectric parameters of breast carcınoma and the surrounding tissues in the frequency range from $100 \mathrm{kHz}$ to $100 \mathrm{MHz}$ [14]

\begin{tabular}{|c|c|c|c|c|c|c|c|}
\hline $\begin{array}{l}\text { Specimen } \\
\text { Location }\end{array}$ & $\begin{array}{c}\text { Sample } \\
\text { No. }\end{array}$ & $\varepsilon_{\delta}$ & $\varepsilon_{\infty}$ & $\tau(\mu \mathrm{s})$ & $\alpha$ & $\begin{array}{c}\sigma_{\mathrm{DC}} \\
(\mathrm{ms} / \mathrm{cm})\end{array}$ & Diagnosis \\
\hline \multirow{6}{*}{ A } & 1 & 6090 & 50 & 0.633 & 0.326 & 2.20 & \multirow{6}{*}{$\begin{array}{l}\text { Infiltrating } \\
\text { ductal } \\
\text { carcinoma } \\
\text { metastases }\end{array}$} \\
\hline & 2 & 8260 & 50 & 0.595 & 0.311 & 3.03 & \\
\hline & 3 & 3720 & 50 & 0.267 & 0.283 & 6.47 & \\
\hline & 4 & 5170 & 50 & 0.288 & 0.239 & 6.91 & \\
\hline & 5 & 3440 & 50 & 0.238 & 0.238 & 7.12 & \\
\hline & 6 & 5710 & 50 & 0.263 & 0.277 & 6.60 & \\
\hline \multirow[b]{2}{*}{ B } & 1 & 3330 & 50 & 1.30 & 0.380 & 3.3 & \multirow{2}{*}{$\begin{array}{l}\text { Infiltrating } \\
\text { ductal } \\
\text { carcinoma }\end{array}$} \\
\hline & 2 & 5510 & 30 & 0.33 & 0.250 & 5.70 & \\
\hline \multirow{3}{*}{ C } & 1 & 793 & 20 & 0.579 & 0.232 & 0.82 & \multirow{3}{*}{$\begin{array}{l}\text { Infiltrating } \\
\text { ductal } \\
\text { carcinoma }\end{array}$} \\
\hline & 2 & 482 & 30 & 0.603 & 0.281 & 0.38 & \\
\hline & 3 & 3310 & 30 & 0.557 & 0.310 & 3.05 & \\
\hline \multirow{4}{*}{ D } & 1 & 2740 & 30 & 0.269 & 0.358 & 3.89 & \multirow{4}{*}{$\begin{array}{l}\text { Infiltrating } \\
\text { lobular } \\
\text { carcinoma }\end{array}$} \\
\hline & 2 & 3285 & 30 & 0.3202 & 0.275 & 5.75 & \\
\hline & 3 & 2320 & 30 & 0.259 & 0.278 & 6.49 & \\
\hline & 4 & 1253 & 319 & 0.670 & 0.400 & 3.52 & \\
\hline \multirow{4}{*}{ E } & 1 & 3125 & 167 & 0.525 & 0.223 & 1.02 & \multirow{4}{*}{$\begin{array}{l}\text { Infiltrating } \\
\text { lobular } \\
\text { carcinoma }\end{array}$} \\
\hline & 2 & 7060 & 30 & 1.605 & 0.362 & 4.99 & \\
\hline & 3 & 13100 & 30 & 1.396 & 0.349 & 6.59 & \\
\hline & 4 & 3080 & 50 & 0.45 & 0.298 & 3.90 & \\
\hline \multirow{3}{*}{$\mathrm{F}$} & 1 & 8830 & 30 & 1.408 & 0.360 & 2.78 & \multirow{3}{*}{$\begin{array}{l}\text { Infiltrating } \\
\text { ductal } \\
\text { carcinoma }\end{array}$} \\
\hline & 2 & 10170 & 30 & 1.210 & 0.340 & 2.73 & \\
\hline & 3 & 180 & 10 & 0.684 & 0.149 & 0.120 & \\
\hline \multirow{6}{*}{ G } & 1 & 288 & 10 & 0.983 & 0.10 & 0.161 & \multirow{6}{*}{$\begin{array}{l}\text { Infiltrating } \\
\text { lobular } \\
\text { carcinoma }\end{array}$} \\
\hline & 2 & 298 & 10 & 1.008 & 0.075 & 0.130 & \\
\hline & 3 & 675 & 10 & 1.391 & 0.163 & 0.444 & \\
\hline & 4 & 7930 & 50 & 1.216 & 0.367 & 5.33 & \\
\hline & 5 & 5490 & 50 & 0.768 & 0.379 & 4.15 & \\
\hline & 6 & 8660 & 50 & 1.415 & 0.331 & 5.16 & \\
\hline
\end{tabular}

\section{SIMULATION MODEL OF BREAST TUMOR}

A hemisphere breast model was designed as showed in Fig. 1 according to the dielectric properties of tissues which are permittivity $(\varepsilon)$ and conductivity $(\sigma)$. Microwave imaging was carried out by transmitting a sequence of 
electromagnetic waves through the breast model and measuring the scattered field on the breast.

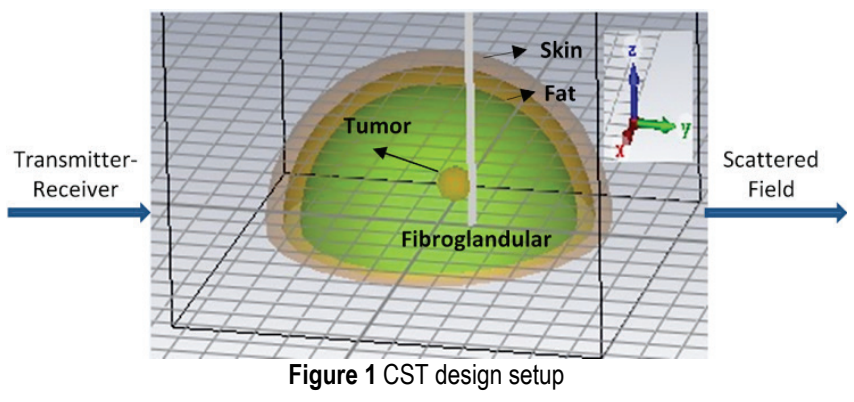

The design points that are the combinations of 10 factors values ranging from their lower values to upper values given in Tab. 2 are generated by experimental design methods by using the Design Expert 7.0 Trial Version. Design space is used in the CST simulation model for assessing the return loss values $(S 11)$. In order to find the input-output relationship, main effects and interactions of factor effects on detecting breast tumor, S11 values obtained from the simulation are entered as experimental design output values. The flow of the method application in this study is given in Fig. 2.

Table 2 Lower and upper bounds for factor values

\begin{tabular}{|c|l|c|c|}
\hline Factor & \multicolumn{1}{|c|}{ Name } & Low Level & High Level \\
\hline A & Skin $\varepsilon$ & 30 & 40 \\
\hline B & Skin $\sigma$ & 3 & 9 \\
\hline C & Fat $\varepsilon$ & 1 & 10 \\
\hline D & Fat $\sigma$ & 0 & 1 \\
\hline E & Fibro $\varepsilon$ & 40 & 50 \\
\hline F & Fibro $\sigma$ & 1.70 & 12 \\
\hline G & Tumor $\varepsilon$ & 40 & 56 \\
\hline H & Tumor $\sigma$ & 3 & 15 \\
\hline J & Breast Radius (cm) & 2.5 & 10 \\
\hline K & Tumor Radius (mm) & 1 & 10 \\
\hline
\end{tabular}

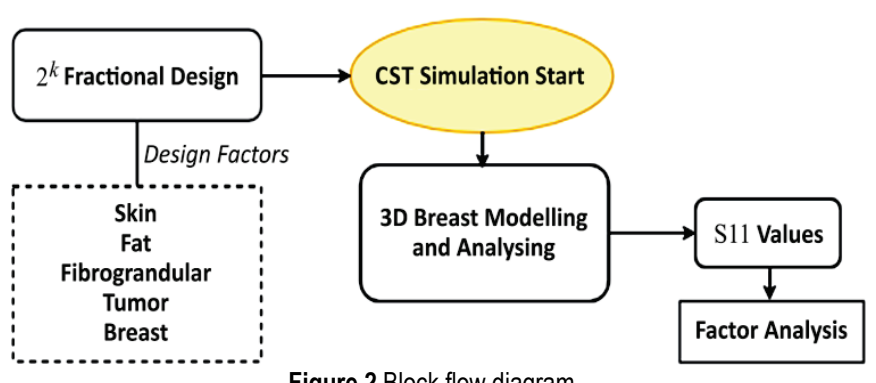

Figure 2 Block flow diagram

\section{RESULTS}

$2^{k}$ factorial design is used with $V$ Resolution in this study. It means that each factor has two levels. In this experiment, there are ten factors, and in order to lessen the number of experiments, we can exclude some design points by using the resolution property of the factorial design technique. Hence, the fractional factorial is used and $2^{10-3}=128$ experiments are conducted. The analysis of variance (ANOVA) results in Tab. 3 show that our model with a $p$-value less than 0.0001 represents the design space significantly. The $p$-values of the factors $A, C, J$ and $K$ are less than 0.05 and they can be concluded as having significant effects with the confidence of 0.95. Thus, Skin $\varepsilon$, Fat $\varepsilon$, BreastRadius and TumorRadius are obtained as main concerns in the detection of breast cancer.

Table 3 Analysis of the variance for the main effects

\begin{tabular}{|l|c|c|c|c|c|}
\hline Source of Variation & $\begin{array}{c}\text { Sum of } \\
\text { Squares }\end{array}$ & d.o.f & $\begin{array}{c}\text { Mean } \\
\text { Square }\end{array}$ & $F$ Value & $\begin{array}{c}p \text {-value } \\
\text { Prob }>F\end{array}$ \\
\hline Model & 3349.53 & 55.00 & 60.90 & 12.56 & $<0.0001$ \\
\hline A-Skin $\varepsilon$ & 39.77 & 1.00 & 39.77 & 8.20 & 0.0055 \\
\hline B-Skin $\sigma$ & 17.34 & 1.00 & 17.34 & 3.58 & 0.0626 \\
\hline C-Fat $\varepsilon$ & 68.71 & 1.00 & 68.71 & 14.17 & 0.0003 \\
\hline D-Fat $\sigma$ & 0.28 & 1.00 & 0.28 & 0.06 & 0.8093 \\
\hline E-Fibro $\varepsilon$ & 13.24 & 1.00 & 13.24 & 2.73 & 0.1029 \\
\hline F-Fibro $\sigma$ & 0.08 & 1.00 & 0.08 & 0.02 & 0.8985 \\
\hline G-Tumor $\varepsilon$ & 10.19 & 1.00 & 10.19 & 2.10 & 0.1516 \\
\hline H-Tumor $\sigma$ & 7.22 & 1.00 & 7.22 & 1.49 & 0.2264 \\
\hline J-BreastRadius & 299.76 & 1.00 & 299.76 & 61.81 & $<0.0001$ \\
\hline K-TumorRadius & 576.77 & 1.00 & 576.77 & 118.92 & $<0.0001$ \\
\hline
\end{tabular}

The graphs of the each significant factor's main effect on the value of $S 11$ is illustrated in Fig. 3. The factors BreastRadius $(J)$ and TumorRadius $(K)$ seem to be more influential than others on the change of the $S 11$ value in terms of their slopes of the lines. However, the difference is that while the $S 11$ value decreases through low-to-high values of BreastRadius (J), the low-to-high values of the TumorRadius $(K)$ increase.

In order not to illustrate all of the two factor interactions, only significant interaction effects of $A J, B D, C E, C J, C K$, $E J, E K$, and $J K$ are given in Tab. 4. The interactions of factors are important to be considered to demonstrate the effect of two factors together on the value of S11. Hence, the significance of two factors may result as lesser or greater than each factor alone.

Table 4 Analysis of the variance for significant interaction effects

\begin{tabular}{|c|c|c|c|c|c|c|}
\hline & $\begin{array}{l}\text { Source of } \\
\text { Variation } \\
\end{array}$ & $\begin{array}{l}\text { Sum of } \\
\text { Squares }\end{array}$ & d.o.f & $\begin{array}{c}\text { Mean } \\
\text { Square } \\
\end{array}$ & $F$ Value & $\begin{array}{c}p \text {-value } \\
\text { Prob }>F\end{array}$ \\
\hline \multirow{9}{*}{ 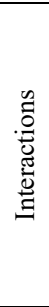 } & Model & 3349.53 & 55.00 & 60.90 & 12.56 & $<0.0001$ \\
\hline & AJ & 44.98 & 1.00 & 44.98 & 9.27 & 0.0032 \\
\hline & $\mathrm{BD}$ & 19.92 & 1.00 & 19.92 & 4.11 & 0.0464 \\
\hline & $\mathrm{CE}$ & 24.20 & 1.00 & 24.20 & 4.99 & 0.0286 \\
\hline & CJ & 75.75 & 1.00 & 75.75 & 15.62 & 0.0002 \\
\hline & CK & 64.90 & 1.00 & 64.90 & 13.38 & 0.0005 \\
\hline & EJ & 40.47 & 1.00 & 40.47 & 8.34 & 0.0051 \\
\hline & EK & 48.40 & 1.00 & 48.40 & 9.98 & 0.0023 \\
\hline & $\mathrm{JK}$ & 1838.38 & 1.00 & 1838.38 & 379.05 & $<0.0001$ \\
\hline
\end{tabular}

In Fig. 4, the graphs of interactions from Tab. 4 are demonstrated. In the AJ interaction graph, Skin $\varepsilon$ has no significant effect on the $S 11$ value for the small size BreastRadius. However, for the large size BreastRadius, the S11 value increases through the low-to-high values of Skin $\varepsilon$. In the $B D$ interaction graph, the $S 11$ value increases at the high value of Fat $\sigma$ through the low-to-high values of Skin $\sigma$ . In the interaction graphs of $C E, C J$ and $C K$, the $S 11$ value increases through the low-to-high values of Fat $\varepsilon$ for the high value Fibro $\varepsilon$, for the large size of BreastRadius and the small size of TumorRadius, respectively. Similarly, in the graph of $E J$ and $E K$ interactions, $S 11$ decreases for the large size of 
BreastRadius and the small size of TumorRadius through the low-to-high values of Fibro $\varepsilon$.

Finally, in the last graph, while BreastRadius is smaller than $8.5 \mathrm{~cm}, S 11$ values for the large size TumorRadius are

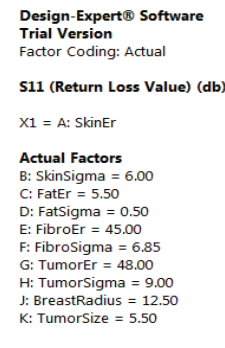

J: BreastRadius $=12.50$
K: Tumorsize $=5.50$
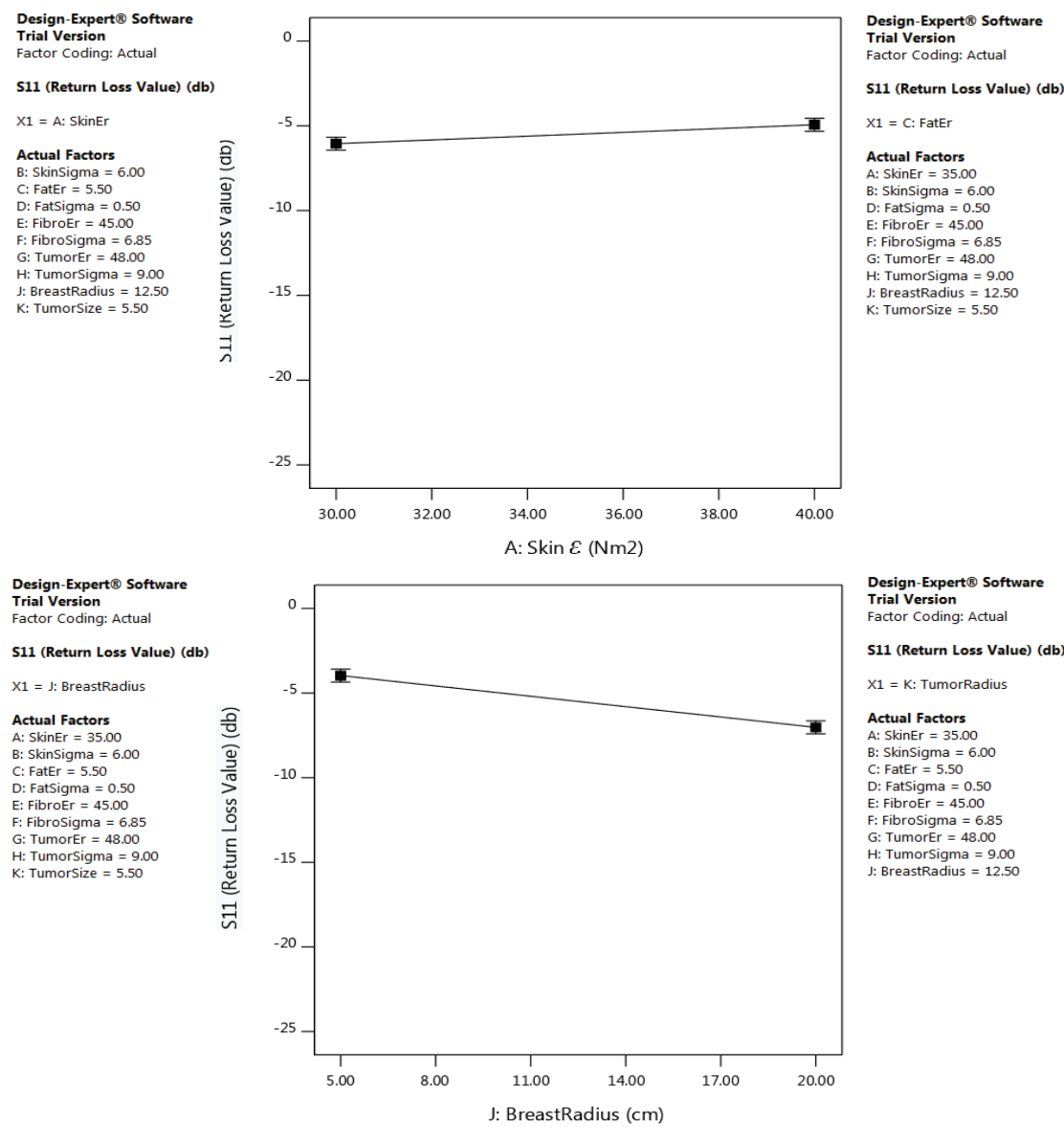

Design-Expertख Software Trial Version S11 (Return Loss Value) (db) $\mathrm{X} 1=\mathrm{K}$ : TumorRadius : SkinEr $=35.00$ FatEr $=5.50$ .

Figure 3 Significant factors' main effects on the detection of breast cancer
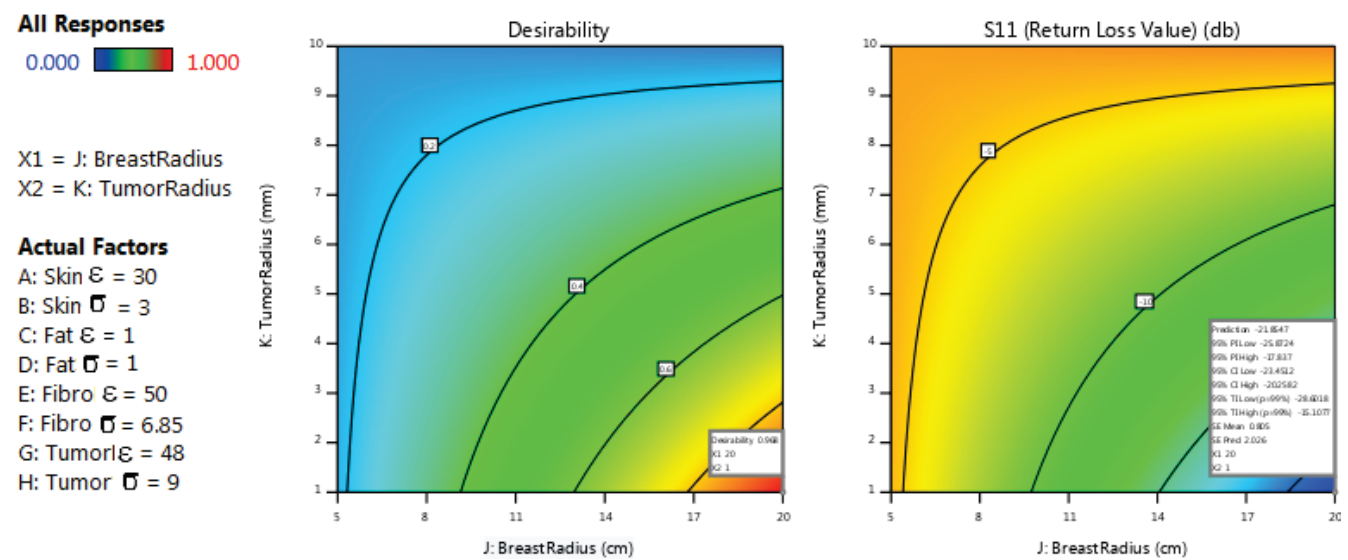

Figure 5 Desirability and optimum surface contours of $S 11$

By using the numerical optimization tool of the Design Expert, the minimum value of $S 11$ is found. In order to have a minimum $S 11$ value, the optimal design points are given in Fig. 5.

The desirability graph based on two most effective factors on breast tumor detection is demonstrated in Fig. 5.
The desired value of $S 11$ is -21.8547 . It is seen that the S11 value decreases at the given values of factors in Fig. 5, and the increasing values of breast radius size and decreasing values of tumor size considerably help the detection of breast tumor. 

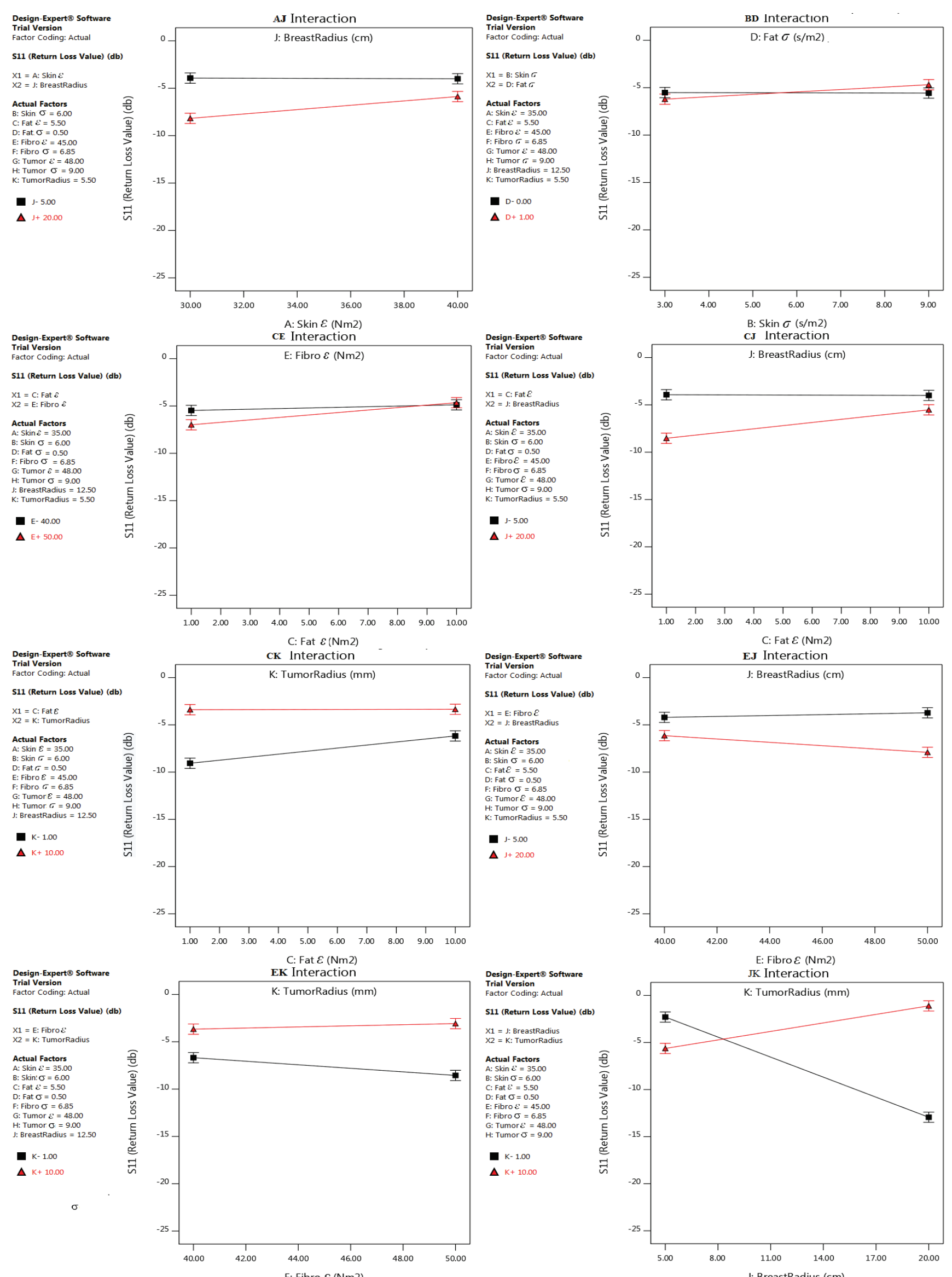

Design-Expert
Trial Version

$\mathrm{x} 1=\mathrm{C}_{\mathrm{N}}$ Fat $\varepsilon$

Actual Factors

$\begin{aligned} \text { A: } \operatorname{Skn} \varepsilon & =35.00 \\ \text { B: Skin } \sigma & =6.00\end{aligned}$

D: Fat $\sigma=0.50$

Fibro $\sigma=6.85$

$\begin{aligned} \text { Tumor } \sigma & =9.00\end{aligned}$

- 5.00

$\Delta+20.00$



C: Fat $\varepsilon(\mathrm{Nm} 2)$

EJ Interaction

Trial Version
Factor Coding: Actual

S11 (Return Loss Value) (db)

$\mathrm{X} 1=\mathrm{C}$ : Fat $\varepsilon$

Actual Factors

$\mathrm{K}+10.00$

Design-Expert

J: BreastRadius (cm)



Design-Expertio Softwar

Factor Coding: Actual

S11 (Return Loss Value) (db)

1 $=$ J: BreastRadius

Actual Factors

A: Skin $\ddot{E}=35.00$

E: Fibro $\tilde{E}=45.00$

G: Tumor $\bar{\varepsilon}=48.00$

- $k-1.00$

$\mathrm{JK}$ Interaction

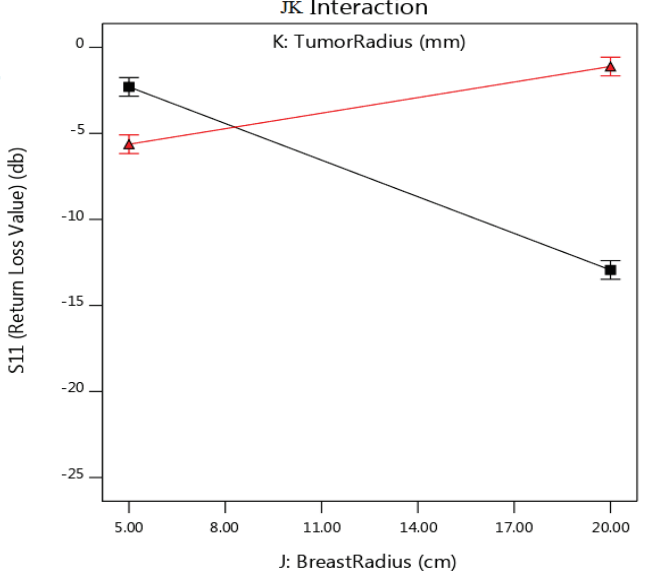

Figure 4 Factors' interaction effects 


\section{CONCLUSION}

Breast cancer is one of the most widespread cancers among females. Various research groups have focused on microwave breast imaging techniques that are non-invasive and harmless to women. The microwave breast imaging technique relies on the differences in the dielectric properties of benign and malignant breast tissues which are skin, fat, fibro glandular, tumor. Breast cancer detection studies were carried out by using dielectric properties of skin, fat, fibro glandular, and tumor tissues. However, the effect of dielectric properties has not been investigated. A 3D-breast was modeled by using the CST STUDIO SUITE electromagnetic simulation software and analyzed by using different dielectric properties and different breast and tumor sizes based on experimental design analyses' results in the frequency range from $0 \mathrm{GHz}$ to $3 \mathrm{GHz}$.

The results of this study show that some factors do not have significant effects on the detection of breast tumor as it was considered in previous studies. The main factors such as fat and skin permittivity, breast and tumor size seem to be important factors among others. Moreover, interaction effects are crucial for observation. However, the effects of some factors change based on low or high the values of others are. For instance, although the effects of the factors fibro permittivity, skin and fat conductivity are not significant alone, their interaction effects are meaningful. Particularly, through the low-to-high values of fibro permittivity with a large size breast and a small size tumor, the return loss value seems to decrease. The effect of the low-to-high values of skin and fat conductivity together increases the return loss value.

In future experiments, the design points can be constructed by using only the significant factors in order to lessen the number of factors and increase the precision of the model. For further studies, a phantom model will be carried out by using the results of this study.

\section{REFERENCES}

[1] Kwon, S. \& Lee, S. (2018). Corrigendum to "Recent Advances in Microwave Imaging for Breast Cancer Detection". International Journal of Biomedical Imaging, 2018, 1-1. https://doi.org/10.1155/2018/1657073

[2] Kim, T., Oh, J., Kim, B., Lee, J., Jeon, S., \& Pack, J. (2008). A study of dielectric properties of fatty, malignant and fibroglandular tissues in female human breast. 2008 Asia-Pacific Symposium on Electromagnetic Compatibility and $19^{\text {th }}$ International Zurich Symposium on Electromagnetic Compatibility. https://doi.org/10.1109/APEMC.2008.4559850

[3] Song, H., Men, A., \& Jiang, Z. (2017). Breast tumor detection using empirical mode decomposition features. IEEE Access, 11. https://doi.org/10.1109/ACCESS.2017.2737633

[4] Kurrant, D. J. \& Fear, E. C. (2011). Regional Estimation of the Dielectric Properties of the Breast: Skin, Adipose, and Fibroglandular Tissues. Proceedings of the $5^{\text {th }}$ European Conference on Antennas and Propagation (EUCAP), 21643342.

[5] Chen, Y., Kosmas, P., \& Martel, S. (2013). Microwave breast tumor detection and size estimation using contrast-agentloaded magnetotactic bacteria. $201335^{\text {th }}$ Annual International
Conference of the IEEE Engineering in Medicine and Biology Society (EMBC). https://doi.org/10.1109/EMBC.2013.6610790

[6] Tayel, M. B. \& Hasan, H. T. (2017). An analytical metalens design approach of CST studio analysis for breast minimum full electric field coverage. $201712^{\text {th }}$ International Conference on Computer Engineering and Systems (ICCES). https://doi.org/10.1109//CCES.2017.8275384

[7] Yousefnia, M., Ebrahimzadeh, A., Dehmollaian, M., \& Madannejad, A. (2018). A Time-Reversal Imaging System for Breast Screening: Theory and Initial Phantom Results. IEEE Transactions on Biomedical Engineering, 65(11), 2542-2551. https://doi.org/10.1109/TBME.2018.2807799

[8] Wang, L. \& Peng, H. (2017). Holographic Microwave Imaging for Breast Cancer Detection Based on Compressive Sensing. Volume 3: Biomedical and Biotechnology Engineering. https://doi.org/10.1115/IMECE2017-70063

[9] Delbary, F., Brignone, M., Bozza, G., Aramini, R., \& Piana, M. (2010). A Visualization Method for Breast Cancer Detection Using Microwaves. SIAM Journal on Applied Mathematics, 70(7), 2509-2533. https://doi.org/10.1137/090774720

[10] Wang, L. (2018). Microwave Sensors for Breast Cancer Detection. Sensors, 18(2), 655. https://doi.org/10.3390/s18020655

[11] von Hippel, A. R. (1954). Dielectric and Waves. MIT Press. New York, 284p.

[12] Nikolova, N. (2011). Microwave Imaging for Breast Cancer. IEEE Microwave Magazine, 12(7), 78-94. https://doi.org/10.1109/MMM.2011.942702

[13] Sha, L., Ward, E., \& Stroy, B. (n.d.). A review of dielectric properties of normal and malignant breast tissue. Proceedings IEEE SoutheastCon 2002 (Cat. No.02CH37283). https://doi.org/10.1109/.2002.995639

[14] Surowiec, A., Stuchly, S., Barr, J., \& Swarup, A. (1988). Dielectric properties of breast carcinoma and the surrounding tissues. IEEE Transactions on Biomedical Engineering, 35(4), 257-263. https://doi.org/10.1109/10.1374

[15] Campbell, A. M. \& Land, D. V. (1992). Dielectric properties of female human breast tissue measured in vitro at 3.2 GHz. Physics in Medicine and Biology, 37(1), 193-210. https://doi.org/10.1088/0031-9155/37/1/014

[16] Sudha, T., Divya, G., Sujaritha, J., \& Duraimurugan, P. (2017). Review of Experimental Design in Analytical Chemistry. Indo American Journal of Pharmaceutical Research, 550-565.

[17] Moore, C. H. (1994). Experimental Design in Healthcare. Quality Management in Healthcare, 2(2), 11- 26.

[18] Apfel, C. C., Korttila, K., Abdalla, M., Kerger, H., Turan, A., M. D., Vedder, I., Zernak, C., Danner, K., Jokela, R., Pocock, S.J., Trenkler, S., Kredel, M., Biedler, A., Sessler, D. I., \& Roewe, N. (2004). A Factorial Trial of Six Interventions for the Prevention of Postoperative Nausea and Vomiting. The New England Journal of Medicine, 350(24), 2441-2451. https://doi.org/10.1056/NEJMoa032196

[19] Aslan, I. (2015). Design of Experiment (DOE) Case Studies in Healthcare. International Review of Social Sciences, 3(7), 287303. 
Author contact:

Nuşin UNCU, Assistant Prof.

Adana Alparslan Türkeş Science and Technology University,

Department of Industrial Engineering,

Balcalı Mahallesi, Çatalan Caddesi No: 201/1,

01250 Sarıçam-Adana/Turkey

nuncu@atu.edu.tr

Emine AVŞAR AYDIN, Assistant Prof.

Corresponding author

Adana Science and Technology University,

Department of Aeronautics Engineering,

Balcalı Mahallesi, Çatalan Caddesi No: 201/1,

01250 Sarıçam-Adana/Turkey

+90-05318436781

eaydin@atu.edu.tr

rasvaenime@gmail.com 